\title{
Fractal Peano Antenna Covered by Two Layers of Modified Ring Resonator
}

\author{
Ammar Nadal Shareef ${ }^{\mathrm{a}}$, Amer Basim Shaalan ${ }^{\mathrm{b}^{*}}$ \\ ${ }^{a}$ Department of General Sciences, Al-Muthanna University,Samawa, Iraq \\ ${ }^{b}$ Physics Department, Al-Muthanna University, Samawa, Iraq
}

\begin{abstract}
Negative index of refraction has attracted a great attention in literatures. These materials are artificial structures named metamaterials has characteristics not found in nature. Microstrip antennas covered by metamaterial are very interesting areas of study. In this paper fractal Peano shape antenna is proposed and covered by two layers of modified ring resonator. The results show an enhancement in Reflection Coefficients, gain, and directivity.
\end{abstract}

Index Terms: Metamaterials, left handed materials, split ring resonators, negative refractive index, fractal antennas.

(C) 2015 Published by MECS Publisher. Selection and/or peer review under responsibility of the Research Association of Modern Education and Computer Science

\section{Introduction}

Few years ago, there is an interest among electromagnetic research groups in the study of Metamaterials as they provide electromagnetic properties not find in natural materials [1]. Simultaneously negative permeability and permittivity over certain frequency range are the most important properties of interest. Veselago while studying this type of materials in 1968 [2], he mentioned to some unique properties like negative refractive index and backward waves. Split ring resonator is regarded as the most known designs to get negative permeability. Several different shapes of split rings are published in literatures to achieve the requirement of negative permeability [3-5].

Classical microstrip patch antennas are the most popular antennas because of several advantages such as low profile, light weight and low cost of fabrication. The addition of a superstrate layer over microstrip patch antenna (MPA) has been reported to enhance antenna gain and radiation efficiency [6-9]. Several configurations of superstrates were used to improve antenna radiation properties, such as dielectric slabs [10], electromagnetic band gap (EBG) structures [11], highly-reflective surfaces [12], and the most recently artificial magnetic superstrates [13].

\footnotetext{
* Corresponding author.

E-mail address: ame72r@gmail.com
} 
Fractal shapes are utilized in antenna design to improve its parameters. In this paper, we introduce modified ring design by adding more spaces to the open side and use it as a superstrate of two layers over fractal antenna shape. This configuration is shown in Fig.1. HFSS software code which is based on finite element modeling was used to calculate $S$ - parameters. Notable enhancement of gain and directivity obtained from this model of fractal antenna shape.

This paper is containing five sections. First section is representing the introduction of the work. Ring design is discussed in section two. Section three explain the fractal antenna design. Results and discussion are presented in section four. Finally, conclusion of this work is presented in section five.

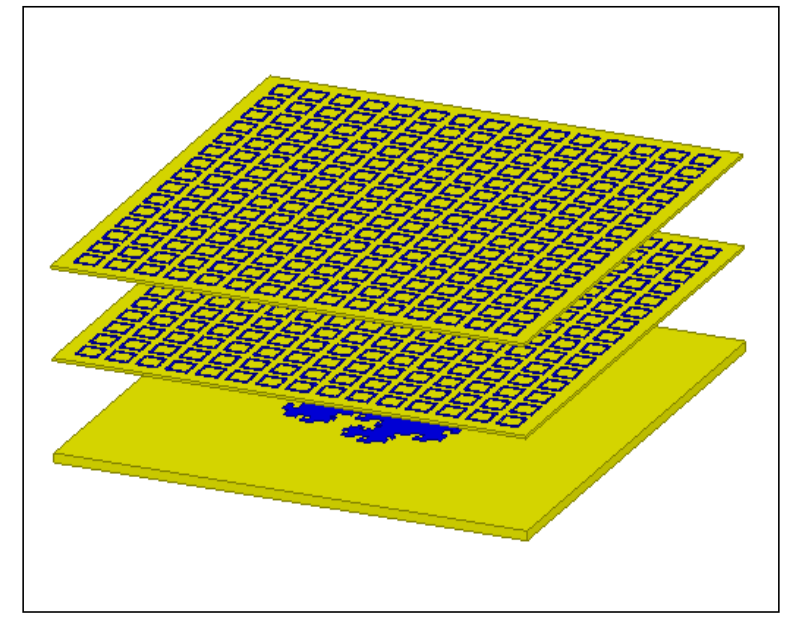

Fig. 1. Configuration of Superstrate Over fractal Antenna Shape

\section{Ring Design}

Dimensions of single unit cell are $4 \mathrm{~mm}$ side length, $0.4 \mathrm{~mm}$ width of side, $0.4 \mathrm{~mm}$ width of the middle space and $0.2 \mathrm{~mm}$ width of extra spaces. We use three and five extra spaces in our design (SRR1, SRR2, SRR3). Three different unit cells are simulated in a waveguide to calculate scattering parameters. Meta-cover (MTM) configuration is shown in Fig.2.

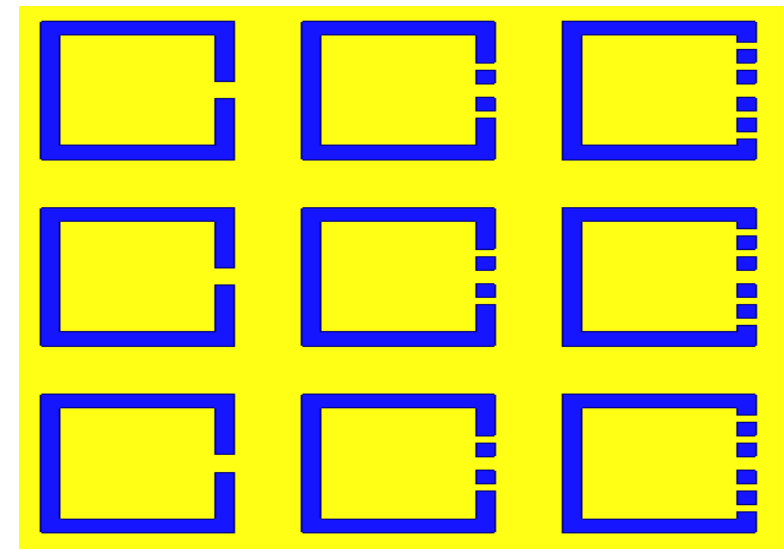

Fig.2. Meta-Cover configuration and unit cell design (SRR1, SRR2, SRR3) 
Unit cells are etched on FR4 substrate $\left(\varepsilon_{\mathrm{r}}=4.4\right)$ of $0.25 \mathrm{~mm}$ thickness. Separation distance between cells is $1.4 \mathrm{~mm}$. 225 cells are distributed to cover the area above Peano antenna. Relative permittivity, relative permeability and refractive index are determined using Nicolson-Ross-Weir approach [14].

$$
\begin{aligned}
& \varepsilon_{\mathrm{r}}=\frac{2}{\mathrm{jkd}} \frac{1-\mathrm{v}_{1}}{1+\mathrm{v}_{1}} \\
& \mu_{\mathrm{r}}=\frac{2}{\mathrm{jkd}} \frac{1-\mathrm{v}_{2}}{1+\mathrm{v}_{2}} \\
& \mathrm{n}= \pm \sqrt{\varepsilon_{\mathrm{r}} \mu_{\mathrm{r}}}
\end{aligned}
$$

Where

$$
\begin{aligned}
& \mathrm{v}_{1}=\mathrm{S}_{21}+\mathrm{S}_{11} \\
& \mathrm{v}_{2}=\mathrm{S}_{21}-\mathrm{S}_{11} \\
& \mathrm{k}=\omega / \mathrm{c}
\end{aligned}
$$

Where $\omega$ is the radian frequency, $d$ is Substrate thickness, and $n$ is the refractive index

\section{Fractal Antenna Design}

In this section, description of fractal shape generation is presented. The starting shape of the antenna is a square has side length equals to $28.5 \mathrm{~mm}$. The generator is a second iteration of Peano curve. The generator is applied to each side of the square to get the final fractal shape of the antenna as shown in Fig.3. The generator is a straight line divided into three segments, the middle one also divided into three segments. Keeping the middle one and removing its neighbors, and then connecting the middle segment with others by using tuning length called indentation width [15]. The shape we get from this process is the generator as shown in Fig.4. Patch antenna etched on substrate of dimensions $60 \mathrm{~mm}$ x $60 \mathrm{~mm}$ x $1.6 \mathrm{~mm}$. Substrate material is FR4 with relative permittivity $\left(\varepsilon_{r}=4.4\right)$.

Fig.3. Fractal Peano Antenna Shape

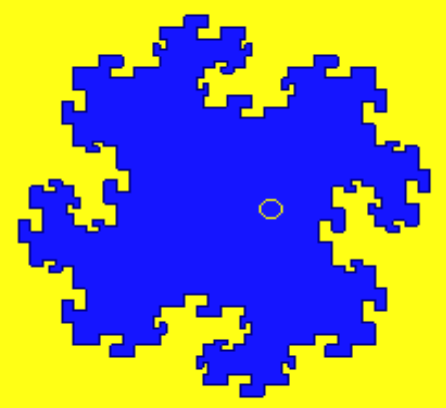




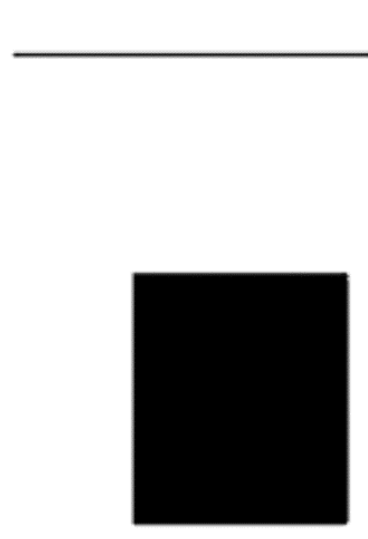

initiator

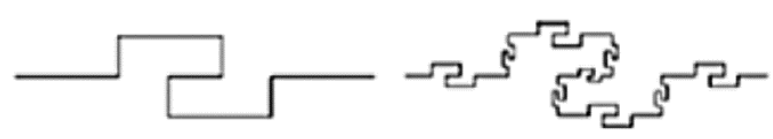

(a)

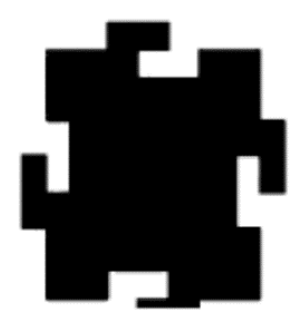

first iteration

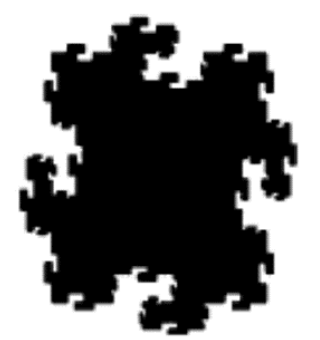

second iteration

(b)

Fig.4. Generator of Fractal Peano Antenna

\section{Results and Discussion}

Two layers of modified rings are designed to be superstrate cover over peano patch antenna. We introduce different shapes of rings. The rings have three and five extra spaces. Calculations shows that the best distance of separation between first cover and the patch is $15 \mathrm{~mm}$. The second cover is placed at $15 \mathrm{~mm}$ above the first one. Fig. 5 shows the resonance frequency of each model of the rings. Fig. 6 shows relative permittivity, relative permeability and refractive index versus the frequency. From these figures, we can see the resonances and negative refractive index lies in the same range of frequency. The bandwidth of negative refractive index is increased when extra spaces are used in the design. Another way to prove left-handed behavior of the material is dispersion diagram. Fig.7 shows the dispersion diagram of SRR1, SRR2, and SRR3 designs. From this figure, we can see the backward radiation of the rings, which is started at the resonant frequency of each ring. The refractive index may has negative values without the simultaneous negative values of real permeability and permittivity $\left(\mu^{\prime}\right.$ and $\left.\varepsilon^{\prime}\right)$. The condition in [16] is utilized to get negative refractive index as seen in (7).

$$
\mu^{\prime} \varepsilon^{\prime \prime}+\mu^{\prime \prime} \varepsilon^{\prime}<0
$$

Where $\mu^{\prime}, \varepsilon^{\prime}$ are real part of permeability and permittivity and $\mu^{\prime \prime}, \varepsilon^{\prime \prime}$ are imaginary part of permeability and permittivity. This condition is plotted versus frequency in Fig.8. Calculations of S-parameters of fractal antenna shape shows a multi band behaviour of this antenna model. It resonates at $7.6 \mathrm{GHz}, 8.2 \mathrm{GHz}, 10 \mathrm{GHz}$, and 11.17 GHz. Fig.9 shows the multiband behaviour of the antenna with meta-cover and without it. Gain and directivity of Peano antenna without meta-cover are listed in Table1. Shapes of radiation patterns are shown in Fig.10. By adding the two layers of meta-cover above the antenna, we obtain enhancement of gain and directivity. Enhancement of gain reach to $11.7 \mathrm{~dB}$ at $8.2 \mathrm{GHz}$. Results of gain and directivity are listed in Table 2. Fig. 11 shows radiation pattern shapes of fractal antenna with meta-cover. Fig. 12 shows three-dimensional far field of the antenna. 


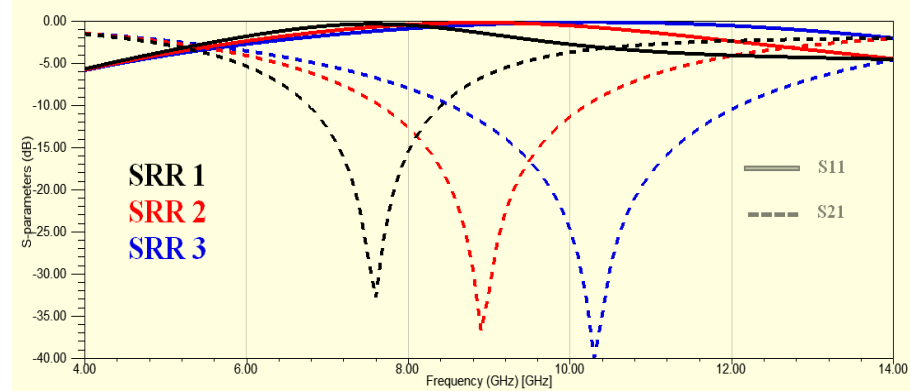

Fig.5. Resonance frequency of SRR1, SRR2, SRR3

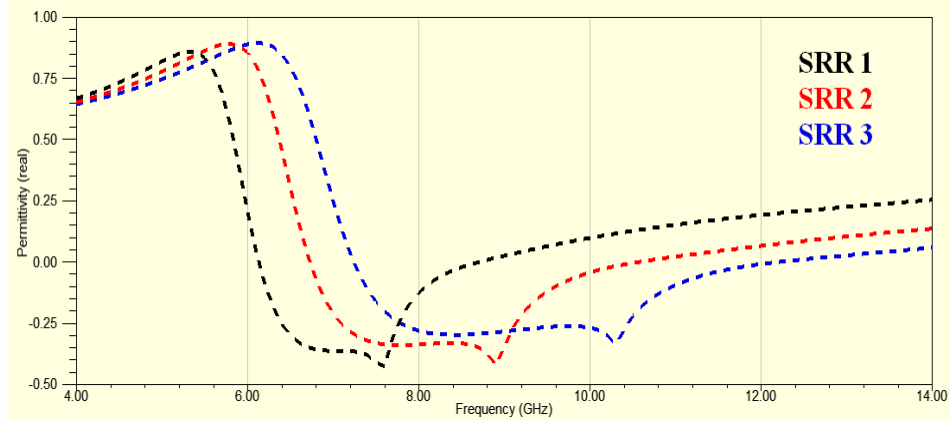

(a). Permittivity

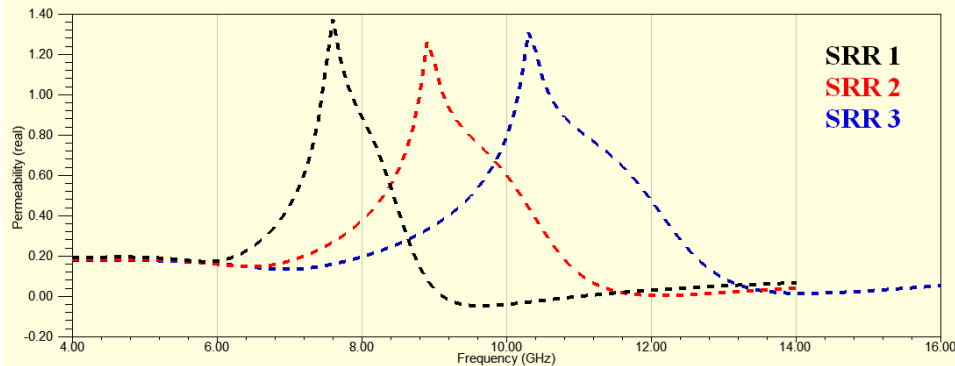

(b). Permeability

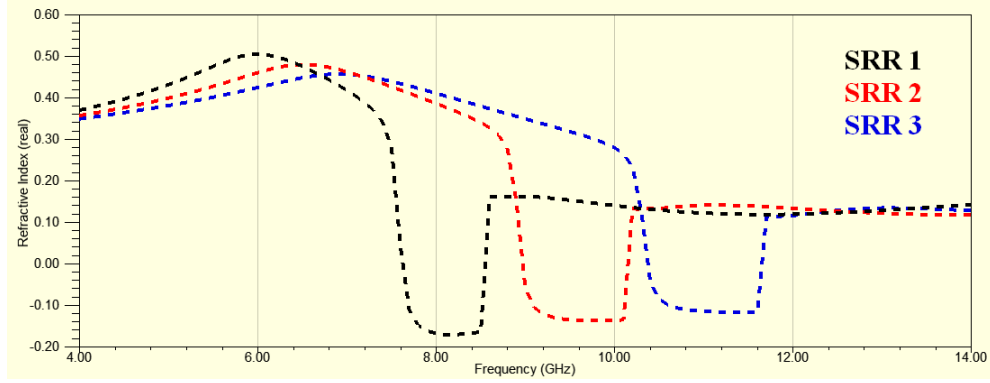

(c). Refractive Index

Fig.6. (a) Relative Permittivity (b) Relative Permeability (c) Refractive index versus Frequency 


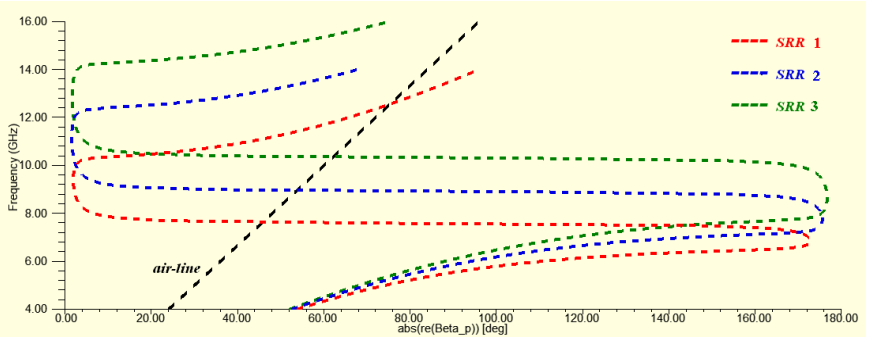

Fig.7. Dispersion diagram

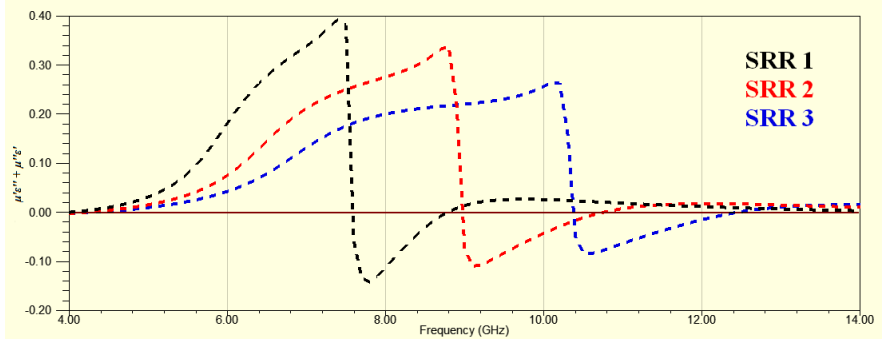

Fig.8. $\mu^{\prime} \varepsilon^{\prime \prime}+\mu^{\prime \prime} \varepsilon^{\prime}$ versus frequency

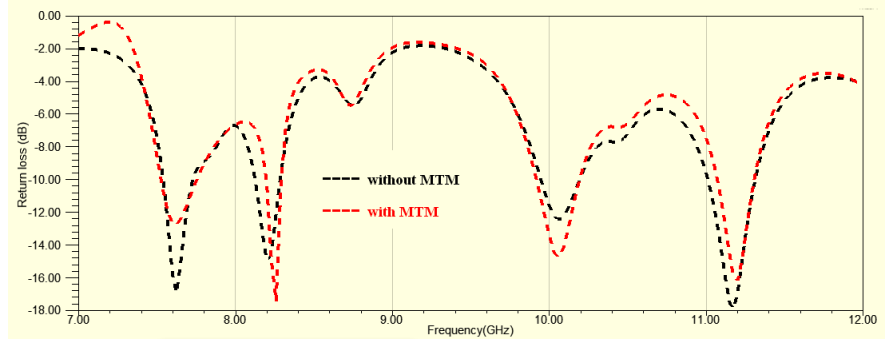

Fig.9. S11versu Frequency of Fractal Antenna without and with meta-cover

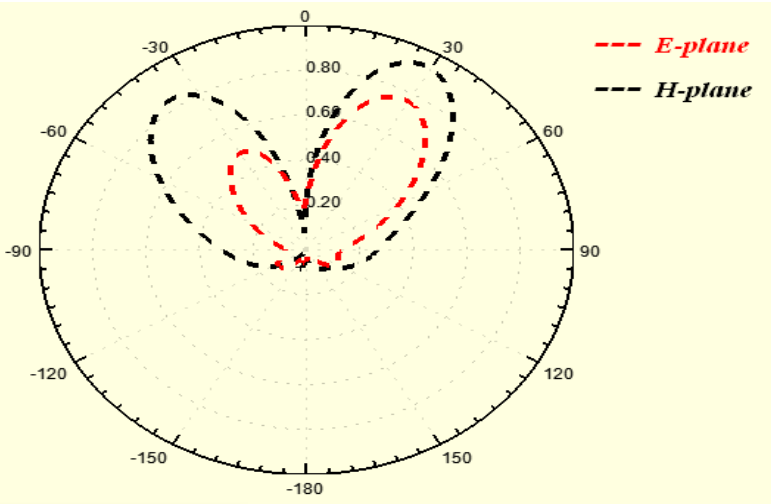

(a) 


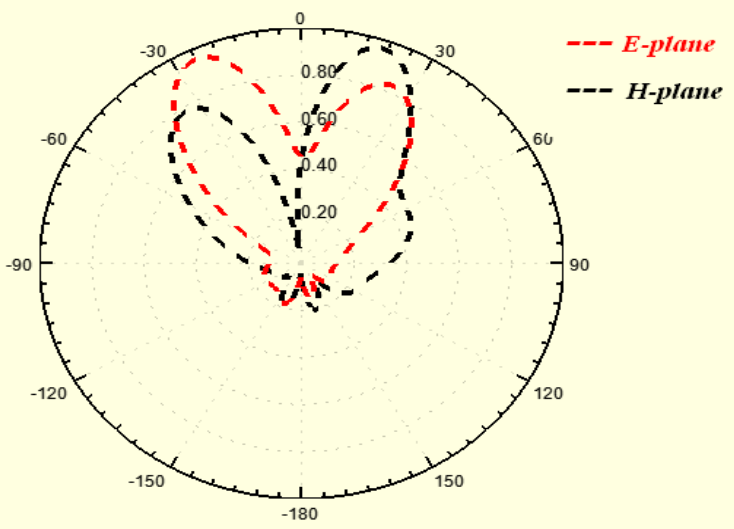

(b)

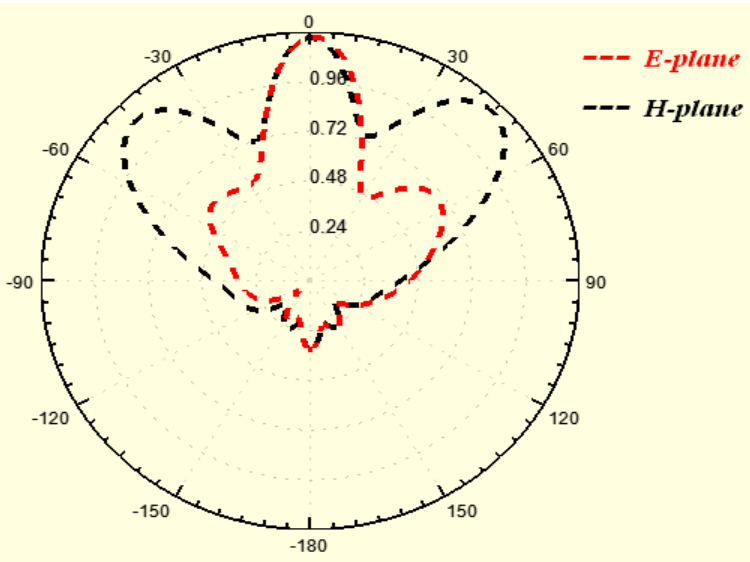

(c)

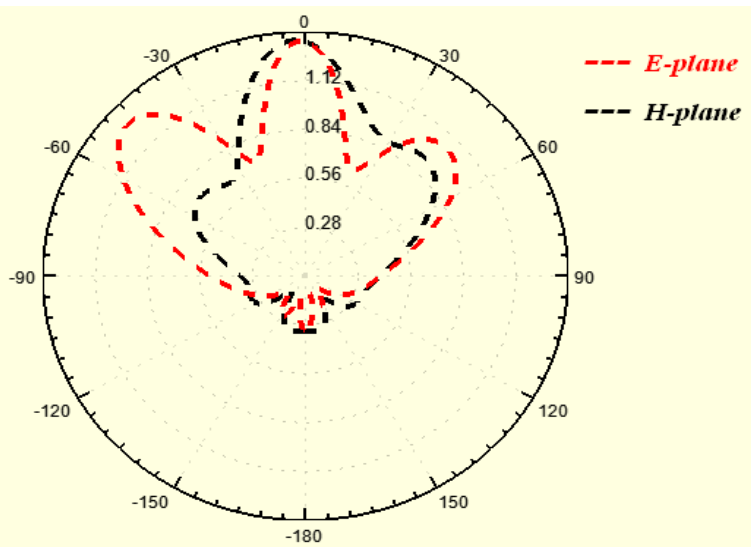

(d)

Fig.10. Radiation Pattern of Fractal Antenna without meta-cover (a) frequency $=7.6 \mathrm{GHz}$ (b) frequency $=8.2 \mathrm{GHz}(\mathrm{c})$ frequency $=10 \mathrm{GHz}$ (d) frequency $=11.17 \mathrm{GHz}$ 


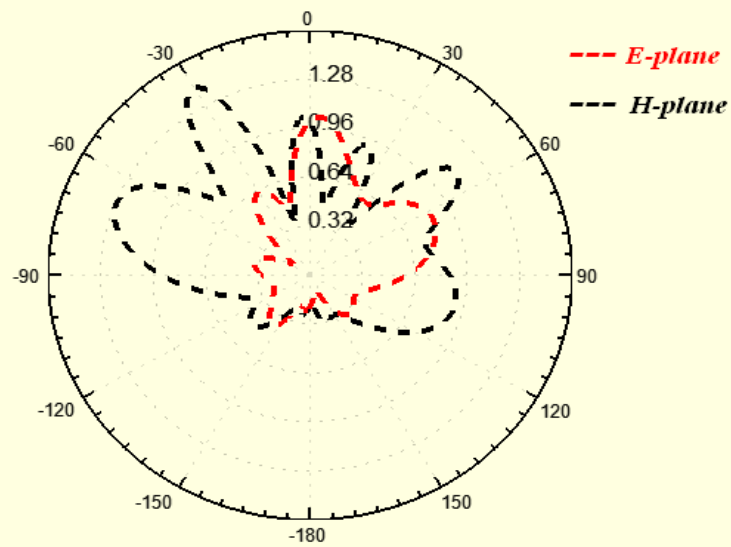

(a)

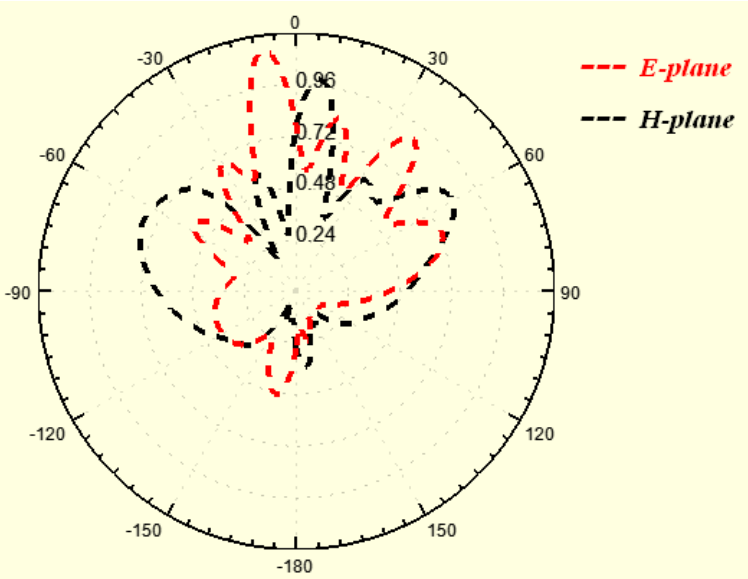

(b)

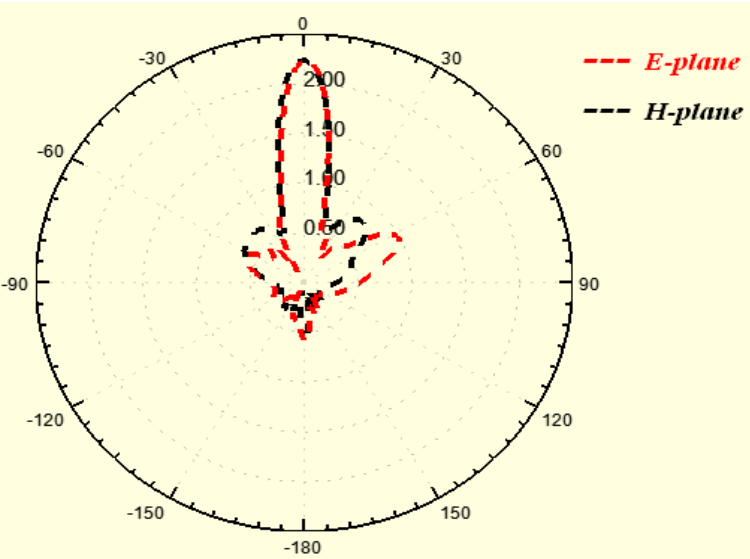

(c) 


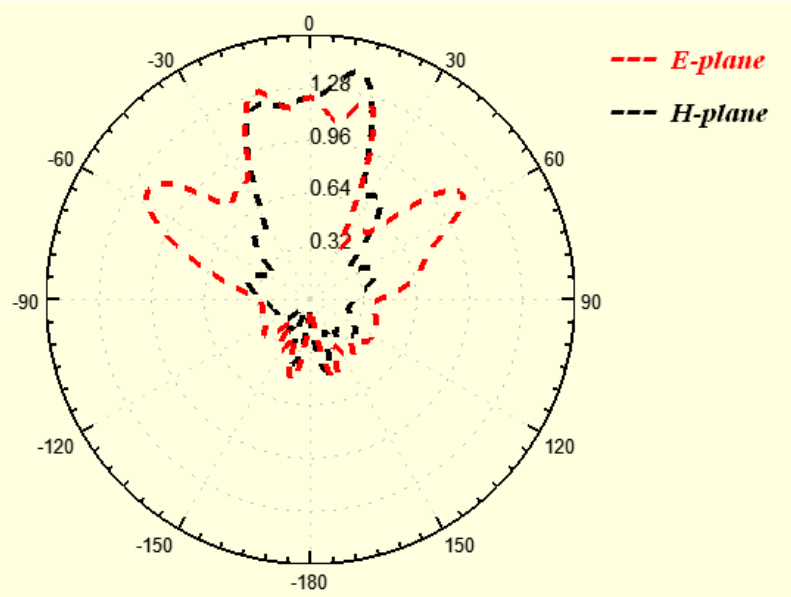

(d)

Fig.11. Radiation Pattern of Fractal Antenna with meta-cover (a) frequency $=7.6 \mathrm{GHz}$ (b) frequency $=8.2 \mathrm{GHz}(\mathrm{c})$ frequency $=10 \mathrm{GHz}$ (d) frequency $=11.17 \mathrm{GHz}$

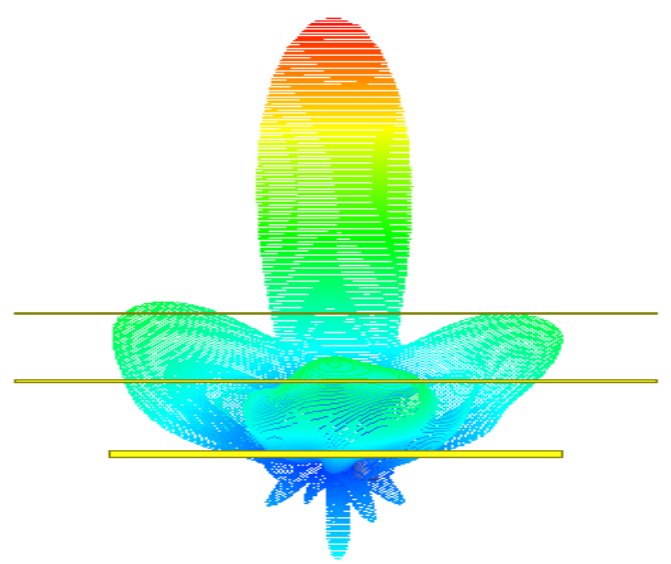

(a)

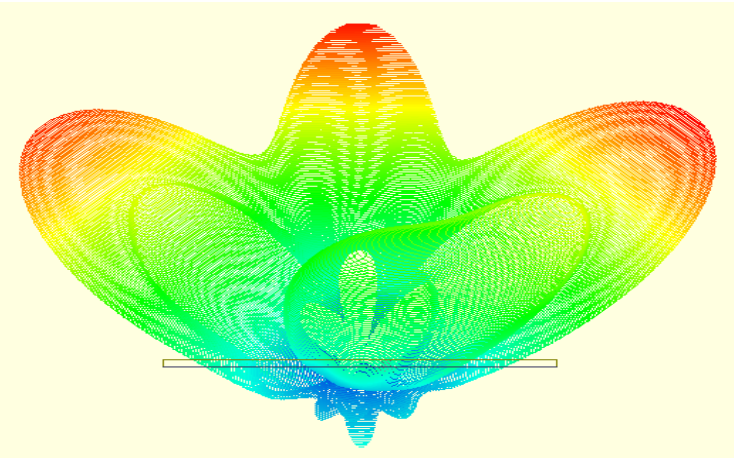

(b)

Fig.12. Three-dimensional far field antenna (a) with $\mathrm{mtm}$ (b) without $\mathrm{mtm}$ 
Table 1. Fractal Antenna Parameters without meta-cover

\begin{tabular}{|c|c|c|c|}
\hline Frequency $(\mathrm{GHz})$ & Gain $(\mathrm{dB})$ & Directivity $(\mathrm{dB})$ & $\mathrm{S}_{11}(\mathrm{~dB})$ \\
\hline 7.6 & 2.3 & 7.9 & -13.9 \\
8.2 & 3.3 & 8.6 & -13 \\
10 & 4.1 & 8 & -15.2 \\
11.17 & 5.7 & 8.5 & -14.5 \\
\hline
\end{tabular}

Table 2. Fractal Antenna Parameters with meta-cover

\begin{tabular}{|c|c|c|c|}
\hline Frequency $(\mathrm{GHz})$ & Gain $(\mathrm{dB})$ & Directivity $(\mathrm{dB})$ & $\mathrm{S}_{11}(\mathrm{~dB})$ \\
\hline 7.6 & 6.7 & 9.2 & -12.7 \\
8.2 & 11.7 & 9.2 & -17.3 \\
10 & 9.3 & 13.7 & -14.7 \\
11.17 & 5.7 & 9.2 & -15.8 \\
\hline
\end{tabular}

\section{Conclusions}

In this paper we use modified rings as two layers of meta-cover over fractal Peano shape antenna. Distance between antenna and first cover is $15 \mathrm{~mm}$. The two layers are separated by $15 \mathrm{~mm}$. Results shows best enhancement in gain and directivity at these distances. enhancement of antenna parameters is related to the extra spaces added to the unit cell of meta-cover. This model is very useful in point-to-point communication and meta-cover can protect the antenna from environment hazards in addition to enhancing antenna parameters. This model is currently under fabrication. Two other models are currently under investigation and will be discussed in future publications.

\section{References}

[1] Veselago V., Braginsky L., Shklover V., and Hafner C., "Negative Refractive Index Materials," Journal of Computational and Theoretical Nanoscience, 2006, Vol.3, pp.1-30.

[2] Veselago V. G., "Electrodynamics of substrates with simultaneously negative values of $\varepsilon$ and $\mu$," Sov. Phys. Usp., 1968, Vol. 10, No. 4, pp.509-514.

[3] Balmaz P. and Martin O., "Electromagnetic resonances in individual and coupled split-ring resonators," JOURNAL OF APPLIED PHYSICS, V. 92, no. 5 pp. 2929-2936.

[4] Wu B., Li B., Su T., and Liang C., "Study on Transmission Characteristic of Split-ring Resonator Defected Ground Structure," PIERS ONLINE, 2006, Vol. 2, no. 6, pp. 710-714.

[5] Bimal G., Singhal P., "Improving Principle Design of Rectangular SRR based Metamaterial Structure with Negative $\mu$ and $\varepsilon$ for Characteristics of Rectangular Microstrip Patch Antenna," International Journal of Engineering Research, Vol.1, no.2, pp. 38-44.

[6] Wu, B-I, Wang W., Pacheco J., Chen X., Grzegorczyk T., and Kong J., "A study of using metamaterials as antenna substrate to enhance gain," Progress in Electromagnetic Research, PIERS 51, 2005, pp. 295-328.

[7] Garg B., Tiwari R., Kumar A., and Chitransh T., "Design of factored 'X' shaped metamaterial structure for enhancement of patch antenna gain," International Conference on Communication Systems and Network Technologies 2011.

[8] Sarkar D., Saurav K., and Vaibhav K., "Design of a Novel Dual-band Microstrip Patch Antenna for WLAN/WiMAX Applications Using Complementary Split Ring Resonators and Partially Defected Ground Structure, " Progress In Electromagnetics Research Symposium proceedings, Taipei, March 25-28,

2013. 
[9] Foroozesh A., and Shafai L., "Effects of artificial magnetic conductors in the design of low-profile highgain planar antennas with high permittivity dielectric superstrate," IEEE Antenna Wireless Propagat.Lett., 2009, vol. 8, pp. $10-13$.

[10] Vettikalladi H., Lafond O., and Himdi M., "High-efficient and high-gain superstrate antenna for 60-ghz indoor communication," IEEE Antenna Wireless Propagat. Lett., 2009, vol. 8, pp. 1422-1425.

[11] Attia H., and Ramahi O. M., "EBG superstrate for gain and bandwidth enhancement of microstrip array antennas," in Proceeding of IEEE AP-S Int. Symp. Antennas Propagation, San Diego, CA, pp. 1-4, 2008.

[12] Foroozesh A., and Shafai L., "Investigation into the effects of the patch type fss superstrate on the highgain cavity resonance antenna design," IEEE Trans. Antennas Propagat., 2010, vol. 58, no. 2, pp. 258270.

[13] Attia H., Yousefi L., Suwailam M. M., Boybay M. S., and Ramahi O. M., "Enhanced-gain microstrip antenna using engineered magnetic superstrates, " IEEE Antenna Wireless Propagat. Lett., 2009, vol. 8, pp. 1198- 1201.

[14] Ziolkwski R. W., "Design, fabrication, and testing of double negative metamaterials," IEEE Transactions on Antennas and Wireless Propagation, 2003, Vol.51, No. 7, 1516-1529.

[15] Barnsley M.F., "Fractals Every Where," Academic press INC., NewYork, 1993.

[16] Nguyen T. T., Lievens1 P., Lee Y. P., and Vu D. L., "Computational studies of a cut-wire pair and combined metamaterials," Advances in Natural Sciences: Nanoscience and Nanotechnology. 2011, Vol. 2, No. 3, p: 9.

\section{Author(s) Profiles}

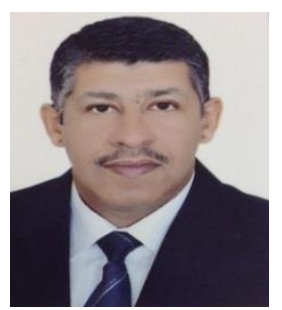

Amer Basim Shaalan was born in Baghdad, Iraq in May of 1972. He received his B.Sc, M.Sc and $\mathrm{PhD}$ degrees in 1994, 1997 and 2002 respectively in Physics from AlMustansiriyah University, Iraq. From 2005-2013, he was head of Physics Department in Al-Muthanna University, Iraq. He was Assistant Prof. since 2008. Sabbatical at Phyladelphia University, Jordan in 2010. His interest area is Fractal antenna and Left handed materials.

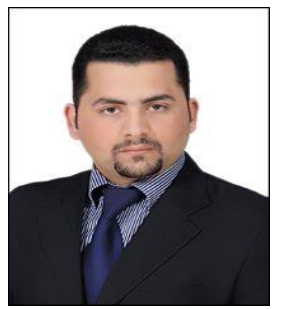

Ammar Nadal Shareef was born in Samawa, Iraq in June of 1983. He received his B.Sc degree in Physics in 2006 from Al-Muthanna University, Iraq. and M.Sc degrees in 2009 in Physics from Basrah University, Iraq. He is currently PhD student. From 2009, he was work in General Science Department in Al-Muthanna University, Iraq. His interest area is Fractal antenna and metamaterial.

How to cite this paper: Ammar Nadal Shareef, Amer Basim Shaalan,"Fractal Peano Antenna Covered by Two Layers of Modified Ring Resonator", IJWMT, vol.5, no.2, pp.1-11, 2015.DOI: 10.5815/ijwmt.2015.02.01 